\title{
Effect of denosumab on trabecular bone score in postmenopausal women with osteoporosis
}

\author{
M. R. McClung ${ }^{1,2}$ • K. Lippuner ${ }^{3}$ M. L. Brandi ${ }^{4}$ J. R. Zanchetta ${ }^{5}$ - H. G. Bone ${ }^{6}$ • \\ R. Chapurlat ${ }^{7}$ - D. Hans ${ }^{8}$ - A. Wang ${ }^{9}$ - C. Zapalowski ${ }^{9,10}$ - C. Libanati ${ }^{9,11}$
}

Received: 11 January 2017 / Accepted: 28 June 2017

(C) International Osteoporosis Foundation and National Osteoporosis Foundation 2017

\begin{abstract}
Summary Trabecular bone score (TBS) assesses bone quality in the lumbar spine using dual-energy X-ray absorptiometry (DXA) scans. In postmenopausal women with osteoporosis, denosumab significantly improved TBS independently of bone mineral density (BMD). This practical technique may have a role in managing patients with osteoporosis.

Introduction TBS, a gray-level texture index determined from lumbar spine DXA scans, correlates with bone microarchitecture and enhances assessment of vertebral fracture risk independently of BMD. In the FREEDOM study, denosumab increased BMD and reduced new vertebral fractures in postmenopausal women with osteoporosis. This retrospective analysis explored the effect
\end{abstract}

\section{R. McClung}

mmcclung.ooc@gmail.com

Oregon Osteoporosis Center, Portland, OR, USA

2 Institute for Health and Ageing, Australian Catholic University, Melbourne, Australia

3 University of Berne, Berne, Switzerland

4 University of Florence, Florence, Italy

5 Instituto de Investigaciones Metabólicas, Buenos Aires, Argentina

6 Michigan Bone and Mineral Clinic, Detroit, MI, USA

7 INSERM UMR 1033, Université de Lyon, Hôpital Edouard Herriot, Lyon, France

8 Lausanne University Hospital, Center of Bone Diseases, Lausanne, Switzerland

9 Amgen Inc., Thousand Oaks, CA, USA

10 Radius Health, Waltham, MA, USA

11 UCB Pharma, Brussels, Belgium of denosumab on TBS and the association between TBS and BMD in FREEDOM.

Methods Postmenopausal women with lumbar spine or total hip BMD T-score $<-2.5$ and -4.0 or higher at both sites received placebo or denosumab $60 \mathrm{mg}$ subcutaneously every 6 months. TBS indices were determined from DXA scans at baseline and months 12,24, and 36 in a subset of 285 women (128 placebo, 157 denosumab) who had TBS values at baseline and $\geq 1$ postbaseline visit.

Results Baseline characteristics were comparable between treatment groups; mean (SD) lumbar spine BMD T-score was $-2.79(0.64)$, and mean (standard deviation [SD]) TBS was 1.200 (0.101) overall. In the placebo group, BMD and TBS increased by $\leq 0.2 \%$ or decreased from baseline at each visit. In the denosumab group, progressive increases from baseline at 12, 24, and 36 months were observed for BMD (5.7, 7.8, and 9.8\%) and TBS (1.4, 1.9, and 2.4\%). Percentage changes in TBS were statistically significant compared with baseline $(p<0.001)$ and placebo $(p \leq 0.014)$. TBS was largely unrelated to BMD, regardless of treatment, either at baseline or for annual changes from baseline (all $r^{2} \leq 0.06$ ).

Conclusions In postmenopausal women with osteoporosis, denosumab significantly improved TBS independently of BMD.

Keywords Denosumab · Postmenopausal women · Trabecular bone score

\section{Introduction}

Measurement of bone mineral density (BMD) using dualenergy X-ray absorptiometry (DXA) is the standard technique to assess bone density and fracture risk in postmenopausal women [1]. Decreased BMD is an established risk factor for 
hip fracture and other osteoporotic fractures [2]. However, use of BMD lacks sensitivity for predicting vertebral fracture [3]. BMD also does not provide insight into bone microstructure and altered bone microarchitecture, which are important factors for fragility fractures [4].

The trabecular bone score (TBS) uses two-dimensional scans obtained during routine DXA for BMD assessment and experimental variograms to characterize the threedimensional rate of gray-level amplitude variations in trabecular bone [5-8]. Projection of healthy bone microstructure onto a plane results in a large number of low-amplitude pixel-to-pixel variations, whereas projection of osteoporotic bone microstructure onto a plane results in a low number of high-amplitude pixel-to-pixel variations in a given direction. Accordingly, an elevated TBS value correlates with better skeletal microstructure, and a lower TBS value correlates with more disrupted and weaker skeletal microstructure [8]. The DXA scans of vertebrae L1-L4 obtained to assess lumbar spine BMD can also be used to generate TBS, thereby producing complementary skeletal information from the same examination [6]. TBS has been shown to be significantly associated with direct measurements of bone microarchitecture and mechanical behavior $[5,8-10]$ and is predictive of current $[6,11-16]$ and future $[17-19]$ fragility fractures in postmenopausal women with primary osteoporosis $[19,20]$. TBS can also be used to assess fracture risk in patients with specific causes of secondary osteoporosis such as hyperparathyroidism, diabetes, and glucocorticoid treatment [21, 22]. TBS increases the ability of the Fracture Risk Assessment Tool (FRAX) to categorize fracture risk, and it has been incorporated into the FRAX model as an adjustment factor [20, 23, 24]. Thus, TBS has been newly included in international guidelines [25], providing an additional tool to identify and improve the characterization of patients at risk for fracture and in need of therapeutic intervention.

Denosumab is a fully human monoclonal antibody against RANK ligand, which is a key mediator of the formation, activation, and survival of osteoclasts [26-29]. In the 3-year FREEDOM study of 7808 postmenopausal women with osteoporosis, subcutaneous administration of denosumab every 6 months was associated with significant reduction in new vertebral and nonvertebral fractures in women with osteoporosis compared with placebo [30]. A subset of women in the FREEDOM study participated in a prospective DXA substudy, in which the results for lumbar spine BMD were comparable to those from the primary study [31]. The objective of this retrospective analysis was to explore the effect of denosumab on TBS and the association between TBS and lumbar spine BMD in FREEDOM. Although denosumab therapy does not improve the trabecular connectivity, resorption spaces and stress risers on trabecular surfaces are filled in, strengthening existing trabeculae. This in-filling of resorption cavities results in slight thickening of trabeculae, at least at the sites of active resorption when denosumab therapy starts, a change that would be reflected in the TBS.

\section{Materials and methods}

\section{Study design}

The study design and primary endpoints of the FREEDOM study [30] and the DXA substudy [31] were reported previously. FREEDOM was an international, multicenter, randomized, double-blind, placebo-controlled study that included 7808 postmenopausal women with osteoporosis. Subjects were randomized 1:1 centrally, in a double-blinded fashion, to receive either denosumab $60 \mathrm{mg}$ or placebo subcutaneously every 6 months for 36 months. All subjects received daily supplementation of calcium $(\geq 1000 \mathrm{mg})$ and vitamin D ( $\geq 400 \mathrm{IU})$.

Of the 213 study centers that participated in the FREEDOM study, 19 centers also participated in the DXA substudy and performed more frequent BMD assessments and evaluations of additional skeletal sites for 441 subjects. These subjects provided separate informed consent to participate in the DXA substudy.

\section{Subjects}

Postmenopausal women with a BMD T-score lower than -2.5 at the lumbar spine or total hip and -4.0 or higher at both sites were eligible for participation in the FREEDOM study if they were naïve to osteoporosis treatment or had received prior bisphosphonate treatment for $<3$ years and not within 12 months of study entry and if they were free of other conditions known to impact bone metabolism. A minimum of two evaluable lumbar vertebrae in the L1-L4 region and one evaluable hip (left or right) was required for inclusion. Subjects with at least one severe or more than two moderate vertebral fractures at screening were excluded.

\section{Study assessments}

Lumbar spine BMD assessments in the DXA substudy of the FREEDOM study were performed at baseline and at 1, 6, 12, 24, and 36 months. BMD was measured by Lunar or Hologic DXA bone densitometers, and the same machine was used for all measurements for an individual subject. Lumbar spine scans included L1-L4 vertebrae; prevalent or incident fractured vertebrae confirmed by X-rays were excluded from the lumbar spine analysis. DXA scans were submitted to a central imaging vendor for analysis (Synarc Inc., San Francisco, CA, USA) who also monitored scanner stability and crosscalibration throughout the study, as well as the quality and 
reliability of the individual subject scans. The results of the DXA substudy have been published [31].

This analysis retrospectively applied software (TBS $\mathrm{iNsight}^{\circledR}$ v1.9, Medimaps, Merignac, France) to lumbar spine DXA scans in a blinded-to-treatment manner to determine the TBS of subjects who participated in the DXA substudy. Lumbar spine TBS was calculated as the mean of the individual measurements for L1-L4 vertebrae, excluding those vertebrae that were not included from BMD assessments because of evidence of fracture or external artifact. However, vertebrae excluded from BMD measurement due to osteophytes or degenerative changes were included in the TBS analyses. Only DXA scans from recent-generation scanners (GE Healthcare Prodigy ${ }^{\mathrm{TM}}$, iDXA ${ }^{\mathrm{TM}}$, Hologic QDR $4500^{\mathrm{TM}}$, Discovery ${ }^{\mathrm{TM}}$, and Horizon ${ }^{\mathrm{TM}}$ ) with sufficient resolution and signal-noise ratio in the acquired scan can be analyzed by the TBS iNsight ${ }^{\circledR}$ software. Because of the post hoc retrospective analysis nature of this study, the DXA scanners were not crosscalibrated using a dedicated TBS fractal phantom.

\section{Statistical analyses}

The analyses included subjects with TBS and lumbar spine BMD measurements at baseline and at least one postbaseline visit. Missing data were not imputed. The percentage changes from baseline in lumbar spine BMD and TBS were analyzed using a repeated-measures model, adjusting for treatment, visit, baseline value, machine type, treatment-by-visit interaction, and baseline value-by-machine type interaction. Statistical inferences on differences relative to placebo at each time point as well as differences relative to baseline were assessed, with no adjustment for multiplicity. The results were reported as least-squares means and associated two-sided $95 \%$ confidence intervals for the treatment difference at each time point. Using the least significant change (LSC) with TBS of 5.82\% identified in a previous study [17], the percentages of subjects with TBS change $\geq$ LSC were calculated for each time point for each treatment group. Pearson correlation coefficients were calculated for the relationships between lumbar spine BMD and TBS at baseline and for the percentage change from baseline.

\section{Results}

Of the 441 postmenopausal women with osteoporosis who participated in the DXA substudy of the FREEDOM study, 285 (128 placebo, 157 denosumab) had measurable TBS data at baseline and at least one postbaseline visit and were included in this analysis. Among these subjects, baseline characteristics were comparable between the placebo and denosumab groups (Table 1). Mean (SD) age at baseline was 72.5 years
Table 1 Baseline characteristics

\begin{tabular}{|c|c|c|}
\hline & $\begin{array}{l}\text { Placebo } \\
(n=128)\end{array}$ & $\begin{array}{l}\text { Denosumab } \\
(n=157)\end{array}$ \\
\hline Age (years), mean $\pm \mathrm{SD}$ & $72.3 \pm 5.4$ & $72.8 \pm 4.7$ \\
\hline $\begin{array}{l}\text { Body mass index }\left(\mathrm{kg} / \mathrm{m}^{2}\right) \\
\quad \text { mean } \pm \mathrm{SD}\end{array}$ & $25.1 \pm 4.3$ & $25.1 \pm 4.1$ \\
\hline \multicolumn{3}{|l|}{ Race, $n(\%)$} \\
\hline White or Caucasian & $108(84.4)$ & $137(87.3)$ \\
\hline Hispanic or Latino & $18(14.1)$ & $19(12.1)$ \\
\hline Other & $2(1.6)$ & $1(0.6)$ \\
\hline Prevalent vertebral fracture, $n(\%)$ & $7(5.5)$ & $12(7.6)$ \\
\hline \multicolumn{3}{|l|}{ Lumbar spine $\mathrm{BMD}$, mean $\pm \mathrm{SD}$} \\
\hline Either machine, T-score & $-2.83 \pm 0.56$ & $-2.75 \pm 0.69$ \\
\hline Hologic $^{\mathrm{a}}\left(\mathrm{g} / \mathrm{cm}^{2}\right)$ & $0.74 \pm 0.06$ & $0.74 \pm 0.07$ \\
\hline $\operatorname{Lunar}^{\mathrm{a}}\left(\mathrm{g} / \mathrm{cm}^{2}\right)$ & $0.83 \pm 0.06$ & $0.86 \pm 0.09$ \\
\hline \multicolumn{3}{|l|}{$\mathrm{TBS}$, mean $\pm \mathrm{SD}$} \\
\hline Either machine & $1.200 \pm 0.099$ & $1.200 \pm 0.103$ \\
\hline Hologic $^{\mathrm{a}}$ & $1.193 \pm 0.099$ & $1.194 \pm 0.103$ \\
\hline Lunar $^{\mathrm{a}}$ & $1.229 \pm 0.093$ & $1.220 \pm 0.102$ \\
\hline
\end{tabular}

$B M D$ bone mineral density, $S D$ standard deviation, $T B S$ trabecular bone score

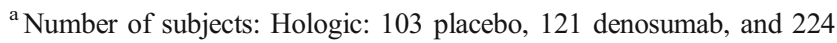
total; Lunar: 25 placebo, 36 denosumab, and 61 total

(5.0). Mean (SD) lumbar spine BMD T-score at baseline was $-2.79(0.64)$, and mean (SD) TBS at baseline was 1.200 (0.101). Mean values at baseline for BMD and TBS were lower for Hologic than Lunar bone densitometers in each treatment group. Except for fewer prevalent vertebral fractures $(6.7$ vs $23.6 \%$ in the entire FREEDOM cohort), the baseline characteristics of patients in the DXA substudy did not differ from those described in FREEDOM [30].

In the denosumab group, progressive increases from baseline at 12, 24, and 36 months were observed for lumbar spine BMD (mean increases of 5.7, 7.8, and 9.8\%, respectively) and TBS (mean increases of 1.4, 1.9, and 2.4\%, respectively) (Fig. 1). The changes in both BMD and TBS in the denosumab group were statistically significant compared with baseline (all $p<0.001$ ) and placebo (all $p \leq 0.014$ ).

More subjects in the denosumab group than in the placebo group had TBS gains of $5.82 \%$ or greater at 12 months (15 vs $11 \% ; p=0.271), 24$ months (21 vs $9 \% ; p=0.012)$, and 36 months ( 20 vs $6 \% ; p=0.001)$.

BMD explained a very small fraction of the variability in TBS at baseline $\left(r^{2}=0.06\right.$; Fig. 2$)$. TBS change was also largely unrelated to BMD change at month $12\left(r^{2}<0.01\right.$ for placebo and $r^{2}=0.03$ for denosumab), month $24\left(r^{2}<0.01\right.$ for placebo and $r^{2}=0.02$ for denosumab), and month 36 $\left(r^{2}=0.03\right.$ for placebo and $r^{2}=0.05$ for denosumab; Fig. 3). 
a $\triangle$ Placebo Q6M $(n=128)$ Denosumab $60 \mathrm{mg}$ Q6M $(n=157)$

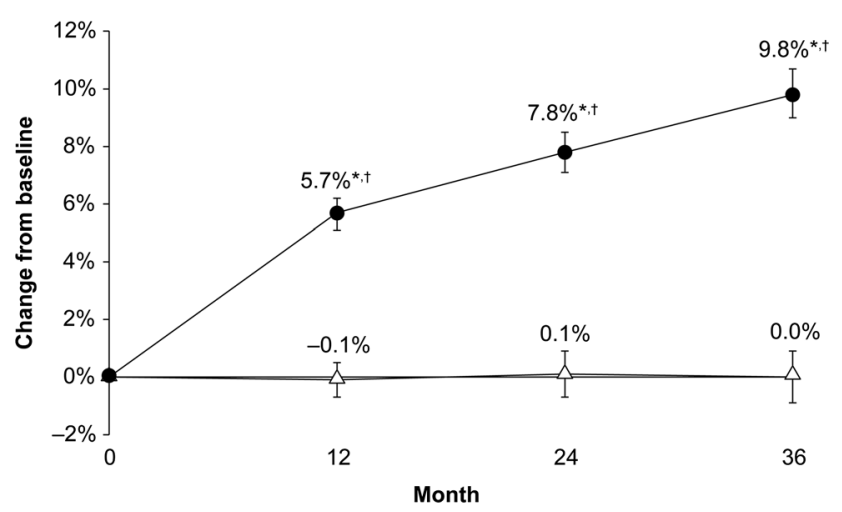

b

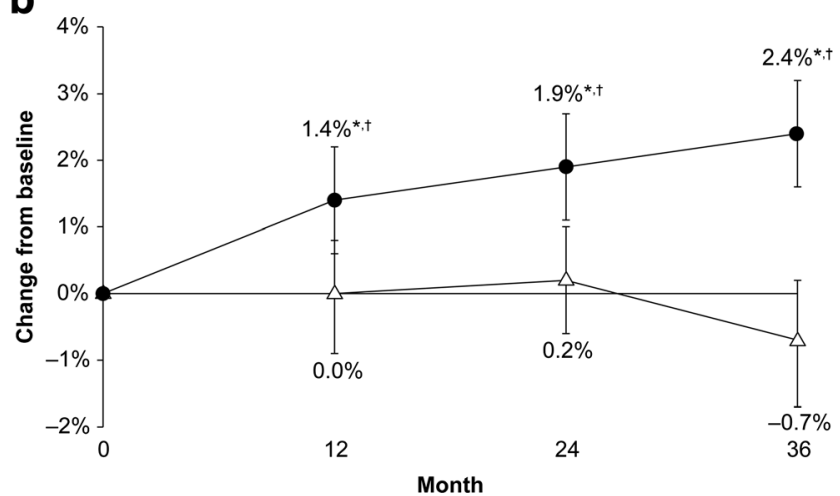

Fig. 1 Percentage change from baseline by visit for lumbar spine BMD (a) and TBS (b) by treatment group. Based on a repeated-measures model adjusting for treatment, visit, baseline value, machine type, treatment-byvisit interaction, and baseline value-by-machine type interaction. Data are presented as least-squares mean and $95 \%$ CI. $* p \leq 0.014$ compared with placebo; ${ }^{\dagger} p<0.001$ compared with baseline. $B M D$ bone mineral density, $C I$ confidence interval, $Q 6 M$ every 6 months, $T B S$ trabecular bone score

\section{Discussion}

In this retrospective analysis of a subset of postmenopausal women with osteoporosis in the FREEDOM study, significant and progressive increases from baseline at 12, 24, and 36 months were observed for both BMD and TBS in the denosumab group.

A previous analysis of 92 women from the FREEDOM study reported that denosumab reduced bone turnover compared with placebo when assessed by bone histomorphometry of iliac crest bone biopsies and analysis of bone turnover markers [32]. Reduced bone turnover and increased BMD following denosumab treatment have been associated with improvement in trabecular and cortical bone at the spine [33] and a significant reduction (68\%) in new vertebral fractures [30].

TBS derived from existing DXA scans of the lumbar spine provides information about bone architecture and fracture risk $[13,17]$, which could assist physicians in identifying patients at risk of fracture [22,25]. TBS has also been shown to reflect therapeutic responses to osteoporosis treatments [34-36] and

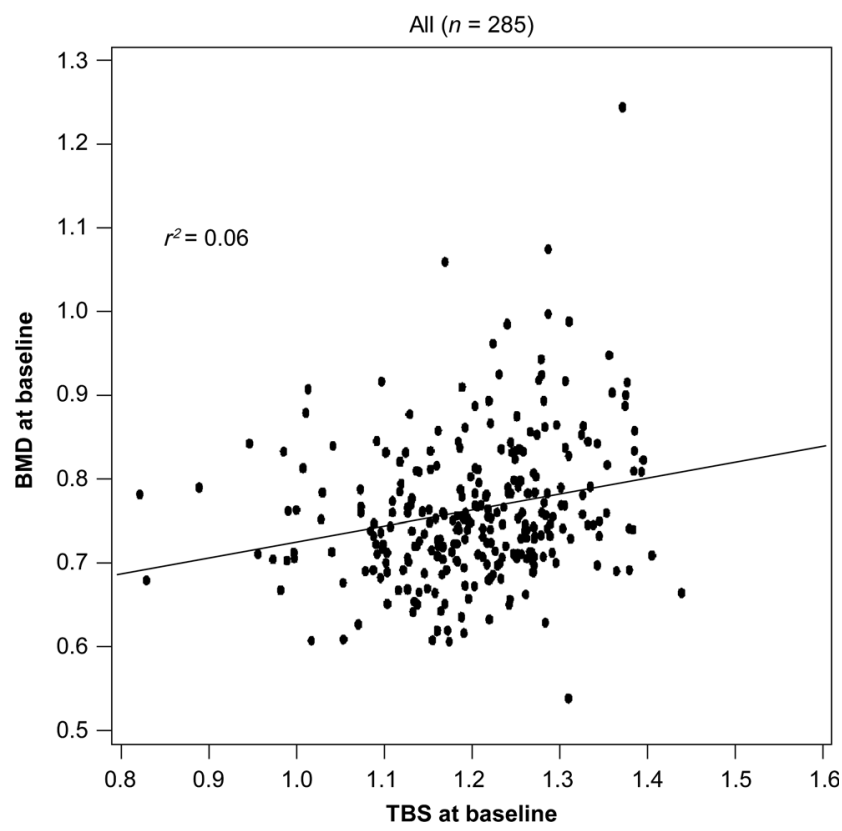

Fig. 2 Relationship between lumbar spine BMD and TBS at baseline. Pearson correlation: $r^{2}=0.06$. $B M D$ bone mineral density, $T B S$ trabecular bone score

could assist in the monitoring of the effectiveness of a therapy. Indeed, pharmacologic intervention studies suggest that TBS improves with treatments that increase BMD, but the magnitude of change is less marked than BMD. The change in TBS also appears to be influenced by the type of therapy for osteoporosis. Previous studies have reported greater improvement in TBS with an anabolic therapy such as teriparatide compared with a bisphosphonate [37, 38]. In this study, denosumab was associated with significantly greater improvement in TBS than placebo at each of the annual assessments. Our findings are consistent with results of an open-label study that investigated different treatments, including denosumab [37]. The results for TBS in this study support its usefulness as an additional tool in routine clinical practice to assess bone microarchitecture noninvasively.

The lack of a significant correlation between TBS and BMD in our study is important for several reasons. Firstly, it supports the principle that TBS provides a measure of bone not captured by densitometric techniques; secondly, it provides complementary information that has proved useful and practical for patient identification [6, 17]; and lastly, it may allow for an improved assessment of differences in responses to diverse therapies for osteoporosis.

A limitation of this analysis was that it included only a small subset of the total FREEDOM population, precluding an assessment of the relationship between changes in TBS and fracture risk reductions. Mean percentage changes from baseline in lumbar spine BMD at 12, 24, and 36 months in this analysis were comparable to those reported previously in the primary analysis of the FREEDOM study [30] and in the 
a $\quad$ Placebo $(n=122)$

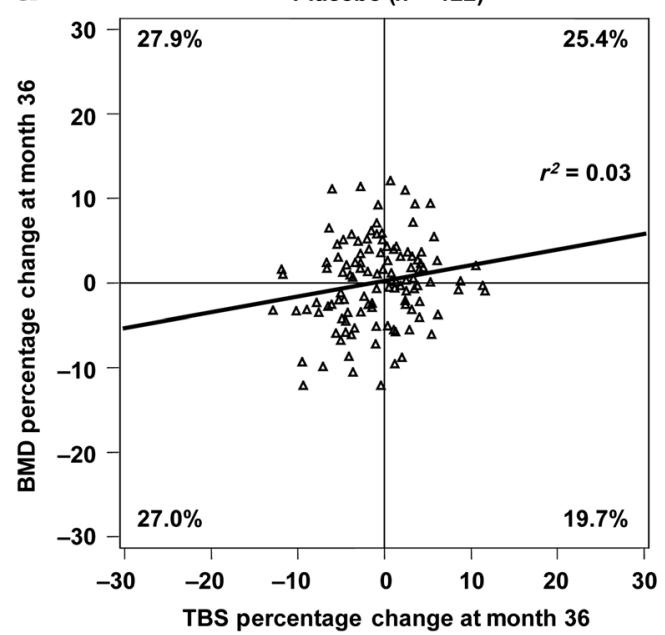

b

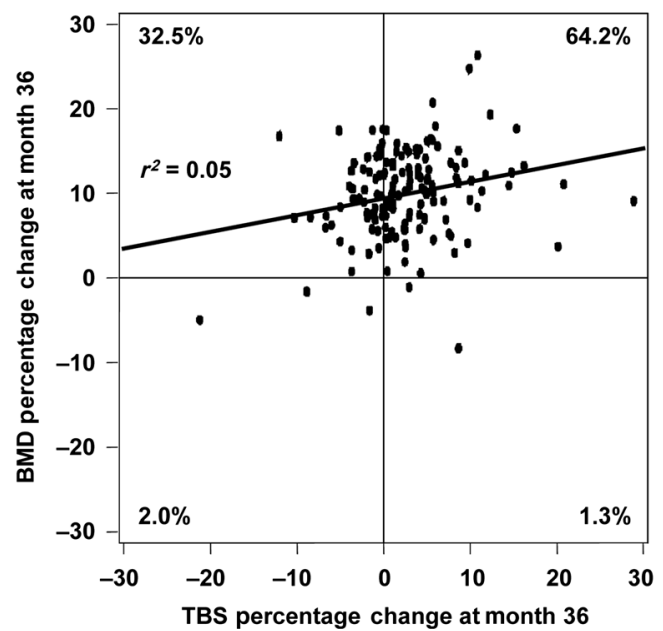

Fig. 3 Relationship between lumbar spine BMD and TBS percentage change from baseline at month 36 by (a) placebo and (b) denosumab. Pearson correlation: $r^{2}=0.03$ (placebo); $r^{2}=0.05$ (denosumab). $B M D$ bone mineral density, TBS trabecular bone score

BMD analysis in the FREEDOM DXA substudy [31]. Because TBS provides distinct information from BMD, it is possible that the other women who participated in FREEDOM could have TBS responses that differed from those observed in this subpopulation. Whereas differences in baseline BMD were observed by machine type in this study, the same machine was used for all measurements for an individual subject, and the analyses were adjusted for machine type and other baseline values. Whereas most subjects had improved BMD with denosumab treatment, approximately one in three subjects did not have improvement in TBS. Changes in BMD have been reported to reflect a large portion of the efficacy of denosumab, with a stronger association for nonvertebral fractures than vertebral fractures [39]. It is possible that the combination of BMD and TBS provides a more complete assessment of fracture risk than either approach alone, but our small study could not determine whether changes in
TBS accounted for any of the remaining effects of treatment on fracture risk.

In conclusion, these analyses showed that denosumab treatment in postmenopausal women results in significant and progressive increases in TBS compared with placebo and baseline over 3 years. TBS is largely unrelated to BMD, either at baseline or for changes from baseline during denosumab treatment, supporting the concept that TBS provides distinct information, independent of BMD. These results, coupled with the previous observations that TBS correlates with fracture risk, suggest that this practical technique may have a role in managing patients with osteoporosis. These results provide impetus for additional investigation of the relationship between changes in TBS and changes in fracture risk during treatment, which if established, could support the use of TBS to assist in selecting the most suitable treatment for an individual patient.

Acknowledgments This work was supported by Amgen Inc. Jonathan Latham (PharmaScribe, LLC, on behalf of Amgen Inc.) and Mandy Suggitt (Amgen Inc.) provided medical writing support.

\section{Compliance with ethical standards}

Ethical approval The study complied with the principles of the Declaration of Helsinki. Institutional review boards and ethics committees approved the protocol and consent process. All procedures performed in studies involving human participants were in accordance with the ethical standards of the institutional and/or national research committee and with the 1964 Helsinki Declaration and its later amendments or comparable ethical standards.

Informed consent Subjects provided informed consent to participate.

Conflicts of interest $\quad$ MR McClung: consultancy_Amgen Inc., Merck, and Radius; and lecture fees-Amgen Inc. and Merck.

K Lippuner: consultancy and principal investigator-Amgen Inc. and MSD.

ML Brandi: research grants-Amgen Inc.

JR Zanchetta: lecture fees-Amgen Inc. and GlaxoSmithKline.

HG Bone: research grants-Amgen Inc. and Merck; consulting fees/honoraria-Amgen Inc., Merck, Radius, and Mission; lecture fees-Amgen Inc.; travel support-Amgen Inc.; fees for review activities-Amgen Inc.; and development of educational presentationsVindico.

R Chapurlat: research grants, travel support, consultancy, and lecture fees-Amgen Inc.

D Hans: received fees per scan from Amgen to make central calculation of TBS on publication; board membership, stock/stock options, and employment-Medimaps Group; and co-owner of the TBS patent.

A Wang: employee and stock/stock options-Amgen Inc.

C Zapalowski: employee-Radius Health; prior employmentAmgen Inc.; and stock/stock options-Amgen Inc. and Radius Health.

C Libanati: employee-UCB Pharma; and stock/stock optionsUCB Pharma and Amgen Inc. 


\section{References}

1. (1994) Assessment of fracture risk and its application to screening for postmenopausal osteoporosis. Report of a WHO Study Group. World Health Organ Tech Rep Ser 843:1-129

2. Johnell O, Kanis JA, Oden A, Johansson H, De Laet C, Delmas P, Eisman JA, Fujiwara S, Kroger H, Mellstrom D, Meunier PJ, Melton LJ 3rd, O'Neill T, Pols H, Reeve J, Silman A, Tenenhouse A (2005) Predictive value of BMD for hip and other fractures. J Bone Miner Res 20:1185-1194

3. Hordon LD, Raisi M, Aaron JE, Paxton SK, Beneton M, Kanis JA (2000) Trabecular architecture in women and men of similar bone mass with and without vertebral fracture: I. Two-dimensional histology. Bone 27:271-276

4. Majumdar S (1998) A review of magnetic resonance (MR) imaging of trabecular bone micro-architecture: contribution to the prediction of biomechanical properties and fracture prevalence. Technol Health Care 6:321-327

5. Pothuaud L, Carceller P, Hans D (2008) Correlations between greylevel variations in $2 \mathrm{D}$ projection images (TBS) and $3 \mathrm{D}$ microarchitecture: applications in the study of human trabecular bone microarchitecture. Bone 42:775-787

6. Pothuaud L, Barthe N, Krieg MA, Mehsen N, Carceller P, Hans D (2009) Evaluation of the potential use of trabecular bone score to complement bone mineral density in the diagnosis of osteoporosis: a preliminary spine BMD-matched, case-control study. J Clin Densitom 12:170-176

7. Winzenrieth R, Michelet F, Hans D (2013) Three-dimensional (3D) microarchitecture correlations with 2D projection image gray-level variations assessed by trabecular bone score using high-resolution computed tomographic acquisitions: effects of resolution and noise. J Clin Densitom 16:287-296

8. Hans D, Barthe N, Boutroy S, Pothuaud L, Winzenrieth R, Krieg MA (2011) Correlations between trabecular bone score, measured using anteroposterior dual-energy X-ray absorptiometry acquisition, and 3-dimensional parameters of bone microarchitecture: an experimental study on human cadaver vertebrae. J Clin Densitom 14:302-312

9. Roux JP, Wegrzyn J, Boutroy S, Bouxsein ML, Hans D, Chapurlat R (2013) The predictive value of trabecular bone score (TBS) on whole lumbar vertebrae mechanics: an ex vivo study. Osteoporos Int 24:2455-2460

10. Muschitz C, Kocijan R, Haschka J, Pahr D, Kaider A, Pietschmann P, Hans D, Muschitz GK, Fahrleitner-Pammer A, Resch H (2015) TBS reflects trabecular microarchitecture in premenopausal women and men with idiopathic osteoporosis and low-traumatic fractures. Bone 79:259-266

11. Nassar K, Paternotte S, Kolta S, Fechtenbaum J, Roux C, Briot K (2014) Added value of trabecular bone score over bone mineral density for identification of vertebral fractures in patients with areal bone mineral density in the non-osteoporotic range. Osteoporos Int 25:243-249

12. Del Rio LM, Winzenrieth R, Cormier C, Di Gregorio S (2013) Is bone microarchitecture status of the lumbar spine assessed by TBS related to femoral neck fracture? A Spanish case-control study. Osteoporos Int 24:991-998

13. Winzenrieth R, Dufour R, Pothuaud L, Hans D (2010) A retrospective case-control study assessing the role of trabecular bone score in postmenopausal Caucasian women with osteopenia: analyzing the odds of vertebral fracture. Calcif Tissue Int 86:104-109

14. Rabier B, Héraud A, Grand-Lenoir C, Winzenrieth R, Hans D (2010) A multicentre, retrospective case-control study assessing the role of trabecular bone score (TBS) in menopausal Caucasian women with low areal bone mineral density (BMDa): analysing the odds of vertebral fracture. Bone 46:176-181
15. Touvier J, Winzenrieth R, Johansson H, Roux JP, Chaintreuil J, Toumi H, Jennane R, Hans D, Lespessailles E (2015) Fracture discrimination by combined bone mineral density (BMD) and microarchitectural texture analysis. Calcif Tissue Int 96:274-283

16. Leib E, Winzenrieth R, Lamy O, Hans D (2014) Comparing bone microarchitecture by trabecular bone score (TBS) in Caucasian American women with and without osteoporotic fractures. Calcif Tissue Int 95:201-208

17. Hans D, Goertzen AL, Krieg MA, Leslie WD (2011) Bone microarchitecture assessed by TBS predicts osteoporotic fractures independent of bone density: the Manitoba study. J Bone Miner Res 26:2762-2769

18. Boutroy S, Hans D, Sornay-Rendu E, Vilayphiou N, Winzenrieth R, Chapurlat R (2013) Trabecular bone score improves fracture risk prediction in non-osteoporotic women: the OFELY study. Osteoporos Int 24:77-85

19. Silva BC, Leslie WD, Resch H, Lamy O, Lesnyak O, Binkley N, McCloskey EV, Kanis JA, Bilezikian JP (2014) Trabecular bone score: a noninvasive analytical method based upon the DXA image. J Bone Miner Res 29:518-530

20. McCloskey EV, Odén A, Harvey NC, Leslie WD, Hans D, Johansson H, Barkmann R, Boutroy S, Brown J, Chapurlat R, Elders PJ, Fujita Y, Glüer CC, Goltzman D, Iki M, Karlsson M, Kindmark A, Kotowicz M, Kurumatani N, Kwok T, Lamy O, Leung J, Lippuner K, Ljunggren O, Lorentzon M, Mellström D, Merlijn T, Oei L, Ohlsson C, Pasco JA, Rivadeneira F, Rosengren B, Sornay-Rendu E, Szulc P, Tamaki J, Kanis JA (2016) A metaanalysis of trabecular bone score in fracture risk prediction and its relationship to FRAX. J Bone Miner Res 31:940-948

21. Ulivieri FM, Silva BC, Sardanelli F, Hans D, Bilezikian JP, Caudarella R (2014) Utility of the trabecular bone score (TBS) in secondary osteoporosis. Endocrine 47:435-448

22. Harvey NC, Glüer CC, Binkley N, McCloskey EV, Brandi ML, Cooper C, Kendler D, Lamy O, Laslop A, Camargos BM, Reginster JY, Rizzoli R, Kanis JA (2015) Trabecular bone score (TBS) as a new complementary approach for osteoporosis evaluation in clinical practice. Bone 78:216-224

23. Leslie WD, Johansson H, Kanis JA, Lamy O, Oden A, McCloskey EV, Hans D (2014) Lumbar spine texture enhances 10-year fracture probability assessment. Osteoporos Int 25:2271-2277

24. McCloskey EV, Odén A, Harvey NC, Leslie WD, Hans D, Johansson H, Kanis JA (2015) Adjusting fracture probability by trabecular bone score. Calcif Tissue Int 96:500-509

25. Silva BC, Broy SB, Boutroy S, Schousboe JT, Shepherd JA, Leslie WD (2015) Fracture risk prediction by non-BMD DXA measures: the 2015 ISCD Official Positions Part 2: trabecular bone score. J Clin Densitom 18:309-330

26. Lacey DL, Timms E, Tan HL, Kelley MJ, Dunstan CR, Burgess T, Elliott R, Colombero A, Elliott G, Scully S, Hsu H, Sullivan J, Hawkins N, Davy E, Capparelli C, Eli A, Qian YX, Kaufman S, Sarosi I, Shalhoub V, Senaldi G, Guo J, Delaney J, Boyle WJ (1998) Osteoprotegerin ligand is a cytokine that regulates osteoclast differentiation and activation. Cell 93:165-176

27. Yasuda H, Shima N, Nakagawa N, Yamaguchi K, Kinosaki M, Mochizuki S, Tomoyasu A, Yano K, Goto M, Murakami A, Tsuda E, Morinaga T, Higashio K, Udagawa N, Takahashi N, Suda T (1998) Osteoclast differentiation factor is a ligand for osteoprotegerin/osteoclastogenesis-inhibitory factor and is identical to TRANCE/RANKL. Proc Natl Acad Sci U S A 95:3597-3602

28. Lacey DL, Tan HL, Lu J, Kaufman S, Van G, Qiu W, Rattan A, Scully S, Fletcher F, Juan T, Kelley M, Burgess TL, Boyle WJ, Polverino AJ (2000) Osteoprotegerin ligand modulates murine osteoclast survival in vitro and in vivo. Am J Pathol 157:435-448

29. Udagawa N, Takahashi N, Yasuda H, Mizuno A, Itoh K, Ueno Y, Shinki T, Gillespie MT, Martin TJ, Higashio K, Suda T (2000) Osteoprotegerin produced by osteoblasts is an important regulator 
in osteoclast development and function. Endocrinology 141:34783484

30. Cummings SR, San Martin J, McClung MR, Siris ES, Eastell R, Reid IR, Delmas P, Zoog HB, Austin M, Wang A, Kutilek S, Adami S, Zanchetta J, Libanati C, Siddhanti S, Christiansen C (2009) Denosumab for prevention of fractures in postmenopausal women with osteoporosis. N Engl J Med 361:756-765

31. Bolognese MA, Teglbjærg CS, Zanchetta JR, Lippuner K, McClung MR, Brandi ML, Høiseth A, Lakatos P, Moffett AH, Lorenc RS, Wang A, Libanati C (2013) Denosumab significantly increases DXA BMD at both trabecular and cortical sites: results from the FREEDOM study. J Clin Densitom 16:147-153

32. Reid IR, Miller PD, Brown JP, Kendler DL, Fahrleitner-Pammer A, Valter I, Maasalu K, Bolognese MA, Woodson G, Bone H, Ding B, Wagman RB, San Martin J, Ominsky MS, Dempster DW (2010) Effects of denosumab on bone histomorphometry: the FREEDOM and STAND studies. J Bone Miner Res 25:2256-2265

33. Keaveny TM, McClung MR, Genant HK, Zanchetta JR, Kendler D, Brown JP, Goemaere S, Recknor C, Brandi ML, Eastell R, Kopperdahl DL, Engelke K, Fuerst T, Radcliffe HS, Libanati C (2014) Femoral and vertebral strength improvements in postmenopausal women with osteoporosis treated with denosumab. J Bone Miner Res 29:158-165

34. Hans D, Krieg M, Lamy O, Felsenberg D (2012) Beneficial effects of strontium ranelate compared to alendronate on trabecular bone score in post menopausal osteoporotic women. A 2-year study (abstract). Osteoporos Int 23(Suppl 2):S266-S267
35. Krieg MA, Aubry-Rozier B, Hans D, Leslie WD, Manitoba Bone Density Program (2013) Effects of anti-resorptive agents on trabecular bone score (TBS) in older women. Osteoporos Int 24:10731078

36. Popp AW, Guler S, Lamy O, Senn C, Buffat H, Perrelet R, Hans D, Lippuner K (2013) Effects of zoledronate versus placebo on spine bone mineral density and microarchitecture assessed by the trabecular bone score in postmenopausal women with osteoporosis: a three-year study. J Bone Miner Res 28:449-454

37. Di Gregorio S, Del Rio L, Rodriguez-Tolra J, Bonel E, García M, Winzenrieth R (2015) Comparison between different bone treatments on areal bone mineral density (aBMD) and bone microarchitectural texture as assessed by the trabecular bone score (TBS). Bone 75:138-143

38. Senn C, Günther B, Popp AW, Perrelet R, Hans D, Lippuner K (2014) Comparative effects of teriparatide and ibandronate on spine bone mineral density (BMD) and microarchitecture (TBS) in postmenopausal women with osteoporosis: a 2-year open-label study. Osteoporos Int 25:1945-1951

39. Austin M, Yang YC, Vittinghoff E, Adami S, Boonen S, Bauer DC, Bianchi G, Bolognese MA, Christiansen C, Eastell R, Grauer A, Hawkins F, Kendler DL, Oliveri B, McClung MR, Reid IR, Siris ES, Zanchetta J, Zerbini CA, Libanati C, Cummings SR, FREEDOM Trial (2012) Relationship between bone mineral density changes with denosumab treatment and risk reduction for vertebral and nonvertebral fractures. J Bone Miner Res 27:687-693 